\title{
Doped Titanium Dioxide Films Prepared by Pulsed Laser Deposition Method
}

\author{
Juguang Hu, ${ }^{1}$ Huabin Tang, ${ }^{1}$ Xiaodong Lin, ${ }^{1}$ Zhongkuan Luo, ${ }^{2}$ Huiqun Cao, ${ }^{2}$ \\ Qiwen Li, ${ }^{1}$ Yi Liu, ${ }^{1}$ Jinghua Long, ${ }^{1}$ and Pei Wang ${ }^{1}$ \\ ${ }^{1}$ College of Physics Science and Technology, Shenzhen University, Guangdong, Shenzhen 518060, China \\ ${ }^{2}$ College of Chemistry and Chemical Engineering, Shenzhen University, Guangdong, Shenzhen 518060, China
}

Correspondence should be addressed to Xiaodong Lin, linxd@szu.edu.cn

Received 28 January 2012; Accepted 2 April 2012

Academic Editor: Baibiao Huang

Copyright (c) 2012 Juguang Hu et al. This is an open access article distributed under the Creative Commons Attribution License, which permits unrestricted use, distribution, and reproduction in any medium, provided the original work is properly cited.

$\mathrm{TiO}_{2}$ was intensively researched especially for photocatalystic applications. The nitrogen-doped $\mathrm{TiO}_{2}$ films prepared by pulsed laser deposition (PLD) method were reviewed, and some recent new experimental results were also presented in this paper. A new optical transmission method for evaluating the photocatalystic activity was presented. The main results are (1) PLD method is versatile for preparing oxide material or complex component films with excellent controllability and high reproducibility. (2) Anatase nitrogen-doped $\mathrm{TiO}_{2}$ films were prepared at room temperature, $200^{\circ} \mathrm{C}$, and $400^{\circ} \mathrm{C}$ by $\mathrm{PLD}$ method using novel ceramic target of mixture of TiN and $\mathrm{TiO}_{2}$. UV/Vis spectra, AFM, Raman spectra, and photocatalystic activity for decomposition of methyl orange (MO) tests showed that visible light response was improved at higher temperature. (3) The automatic, continuous optical transmission autorecorder method is suitable for detecting the photodecomposition dynamic process of organic compound.

\section{Introduction}

1.1. General Description of Preparation of $\mathrm{TiO}_{2}$ Films. In recent years, the field of photocatalysis has became an extremely well-researched field due to wide application interest in self-cleaning surfaces, water or air purification, self-sterilizing surfaces, antifogging surfaces, optical or gas sensor [1-4], and so forth. $\mathrm{TiO}_{2}$ is a fascinating material that has been intensively researched by worldwide researchers. For photocatalystic applications, much attention has been paid to prepare and use $\mathrm{TiO}_{2}$ powder, for it has large specific area $[5,6]$, but it has shortcoming of difficulty to recycle in aqueous fluid. $\mathrm{TiO}_{2}$ films have been prepared by many technologies, including chemical bath deposition (CBD) method [7, 8], electron-beam evaporation [9], reactive electron beam evaporation [10], magnetron sputtering [11, 12], sol-gel [6, 9, 13-17], and thermal oxidation [18, 19].

Much effort has been given to understanding and altering the optical properties of titanium dioxide, especially for enhancing visible light absorption mainly by narrowing the band gap $(3.2 \mathrm{eV})$ for using the economical and ecological sunlight. Theoretical calculations have been performed to clarify the effect of anion doping of $\mathrm{TiO}_{2}$ on band gap modifications [20-22].

Nitrogen-doped $\mathrm{TiO}_{2}$ materials were intensively researched since Asahi et al. proposed that it has narrow band gap and little recombination of electrons and holes [23]. However, Batzill et al. reported that no band gap narrowing is observed for $\mathrm{N}$-doped $\mathrm{TiO}_{2}$ single crystals, but $\mathrm{N}$-doping induces localized $\mathrm{N} 2 \mathrm{p}$ states within the band gap just above the valence band (VB). $\mathrm{N}$ is present in an N(III) valence state, which facilitates the formation of oxygen vacancies and $\mathrm{Ti} 3 \mathrm{~d}$ band gap states at elevated temperatures. This thermal instability may degrade the catalyst during applications [24]. Socol et al. proposed that both substitutional $\mathrm{N}$ and $\mathrm{O}$ vacancies contribute to the visible light absorption [25]. The width of the $\mathrm{TiO}_{2}$ band gap was not affected by the presence of fluorine either, as reported by Todorova et al. [5]. The red shift of the absorption edge was attributed to the increased rutile content in the fluorine-doped $\mathrm{TiO}_{2}$ powers. The codoping effect between nitrogen and hydrogen is responsible for the 
enhanced photoactivity of $\mathrm{N}$-doped $\mathrm{TiO}_{2}$ in the range of visible light [26].

Balek et al. prepared nitrogen and fluorine codoped titania photocatalyst samples for air purification by spray pyrolysis method [27]. A high photocatalytic activity in a visible light region of spectrum depended on the spray pyrolysis temperature and can be ascribed to a synergetic effect of nitrogen and fluorine doping. Synergetic effect also happened in $\mathrm{Nd}_{2} \mathrm{O}_{3}$ modified $\mathrm{TiO}_{2}$ nanoparticles, formation of the surface anatase/rutile phase junction favors photoinduced charge separation and further improves its photocatalytic activity [28].

$\mathrm{Qu}$ et al. prepared $\mathrm{Fe}(3+)$ and $\mathrm{Ce}(3+)$ codoped nanostructure titanium dioxide films via the improved sol-gel process. The samples had smaller crystal size, larger surface area, and larger pore volume. They also found that codoped ions could obviously not only suppress the formation of brookite phase but also inhibit the transformation of anatase to rutile at high temperature. $\mathrm{Fe}(3+) / \mathrm{Ce}(3+)$ codoped $\mathrm{TiO}_{2}$ film showed excellent photocatalytic activity compared with pure $\mathrm{TiO}_{2}$ film, $\mathrm{Fe}(3+)$ or $\mathrm{Ce}(3+)$ single doped $\mathrm{TiO}_{2}$ film. They concluded that the surface microstructure of the films and improved sol-gel process ions doping methods are responsible for improving the photocatalytic activity [29].

Our group has reported works about hydrophilicity between titanium oxide coatings with and without addition of silica. Through the investigation of change of water contact angle on the surface after UV exposure and sunlight radiation, it can be concluded that hydrophilicity of mixed coatings with low-temperature heat treatment of titanium oxide and silica is much better than a pure titanium oxide coating. This effect makes for an improved self-cleaning coating under natural sunlight. The mechanism is that particles of titanium oxide separated by silica reduce the contact chance of recombination of electrons and holes, thereby increasing the photocatalytic action on organic compounds. The addition of silica increases water absorption in the coating. Water molecules absorbed by silica will be photocatalyzed to free hydroxyl groups under the illumination of UV light. These groups benefit the hydrophilicity of coating [30].

As for photo-induced hydrophilic effect, Fujishima et al. have reached the conclusion that there is an aspect of this effect that does not involve simply the cleaning of the surface. The precise nature of the effect has not been elucidated even now, but researchers proposed that the surface species are basically the same ones involved with conventional photocatalysis [2]. Hendersonpresented recent research highlights of the significant insights obtained from molecular-level studies of $\mathrm{TiO}_{2}$ photocatalysis. This comprehensive review has illustrated how a surface science perspective on $\mathrm{TiO}_{2}$ photocatalysis can provide unique insights and motivate more fundamental research in photocatalysis [3].

1.2. $\mathrm{TiO}_{2}$ Films Prepared by PLD Method. PLD technique is a versatile tool for preparing thin-films, because it is capable of preparing films with various properties by simply adjusting the deposition conditions, like the type of target, type of substrate and its temperature, distance between the target and substrate, type and pressure of ambient air, and laser wavelength, and so forth. Its advantages for the film growth of oxides and other multicomponent materials include stoichiometric transfer, growth from an energetic plasma plume, reactive deposition, good adherence to the substrate surface, excellent controllability, and high reproducibility. PLD has played a significant role in advancing our understanding of the physics of the thin-film structures, the material science of a new system, and so forth [31].

With the use of PLD, $\mathrm{TiO}_{2}$ films doped with metal, transition metal, or nonmetallic elements have been prepared, and their properties were controlled by varying the preparing parameters [25]. Socol et al. have grown crystalline anatase phase $\mathrm{TiO}_{2}$ thin films by PLD technique in oxygen, nitrogen, and methane and nitrogen with oxygen mixture. Their studies proved the positive influence of anion doping on the photoreduction activity under visible light exposure. The best photoactivity under visible light exposure was obtained for films deposited in pure nitrogen, which was correlated with the highest red-shift $(480 \mathrm{~nm})$ of the absorption edge and the larger nitrogen incorporation characteristic to these films. Quite different evolutions were observed in case of UV light irradiation. Significant results were obtained in this case for the films deposited in pure oxygen or methane, while the photoactivity (quantum yield) of the films deposited in nitrogen was lower as compared with the blank.

Sato et al. prepared $\mathrm{N}$-doped $\mathrm{TiO}_{2}$ films by the atmospheric controlled PLD (AC-PLD) method to generate visible light active photocatalytic films [32]. For nitrogen doping, the use of $\mathrm{CH}(3) \mathrm{CN}$ gas was found to be more effective than the use of $\mathrm{NH}(3)$. The visible light absorption properties of the films were very sensitive to the $\mathrm{CH}(3) \mathrm{CN}$ partial pressure during ablation. When using $\mathrm{CH}(3) \mathrm{CN}$, nitrogen and an equal quantity of carbon was uniformly doped into the $\mathrm{TiO}_{2}$ films. The resultant films showed better catalytic performance than those which were either undoped or doped using $\mathrm{NH}(3)$. It is also suggested that stronger reducing agents such as carbon are required for doping nitrogen into $\mathrm{TiO}_{2}$ films.

Metal nanoparticles can act as electron traps due to the formation of a Schottky barrier at the metal-semiconductor contact. Holes can decompose organic substances more efficiently, because it has strong oxidative power. Sauthier et al. used PLD technique to prepare $\mathrm{Ag}-\mathrm{TiO}_{2}$ nanocomposites to improve photocatalytic activity and compared with that of bare $\mathrm{TiO}_{2}$ [33]. It was proposed that two distinct mechanisms can contribute to the enhanced photoreactivity under near-UV irradiation. The first is Ag NPs retard electronhole recombination by photogenerated electron transfer from $\mathrm{TiO}_{2}$. And the second one is localized surface plasma resonance absorption of Ag NPs, which can have positive effect on the photocatalytic activity.

The films with more clusters exhibited higher photocatalytic performances than the films with less clusters [34]. The author pointed out that the specific surface area of the films was increased by the deposition of clusters. The larger contact area induces high decomposition rate [35]. It is interesting that the clusters formed in PLD method are not desirable in other semiconductor industrial fields, like 
solar cell and so forth, where smooth and uniform surface is desirable [36]. Suda et al. found that the particle size is changed with the substrate temperature, and larger particle size was obtained at higher temperature [37]. Table 1 lists part of the publications about the preparation of $\mathrm{TiO}_{2}$ films by PLD method in recent years.

Chen et al. obtained heavily nitrogen doped of about $15 \%$ anatase $\mathrm{TiO}_{2}$ films by using TiN target. Different from using $\mathrm{N}_{2}$ gas as $\mathrm{N}$ source, TiN target as solid source might provide reactive molecular or cluster species with Ti-N bonds [43]. Suda et al. measured depth profiles of the prepared films by XPS and found that the film prepared using $\mathrm{TiO}_{2}$ target has little nitrogen, while the film prepared using TiN target has almost $8 \%$ atomic ratio of nitrogen [37]. Somekawa et al. proposed that the $\mathrm{N}$-doping occurred when $\mathrm{N}$ species and $\mathrm{TiO}_{2}$ particles collide on the substrate [46]. We consider that when the laser pulse irradiate onto the solid $\mathrm{N}$ source, $\mathrm{N}$ ion with high energy is produced and ejects to the substrate. It is quite easier to migrate and incorporate into the film lattice than using the $\mathrm{N}_{2}$ or $\mathrm{NH}_{3}$ gas as $\mathrm{N}$ source.

One advantage of PLD technique is that there is stoichiometric transfer of material from target to film [31]. For preparing $\mathrm{N}$-doped $\mathrm{TiO}_{2}$ films, we used a novel type of target, ceramic target mixture of $\mathrm{TiN}$ and $\mathrm{TiO}_{2}$ (molar ratio $1: 3$ ), different from pure $\mathrm{TiN}$ or $\mathrm{TiO}_{2}$ targets used by other researchers $[37,43]$. Energetic $\mathrm{N}$ ion, $\mathrm{O}$ ion, and $\mathrm{Ti}$ ion, produced at the same time with high-intensity pulsed laser irradiation may promote the growth of doped $\mathrm{TiO}_{2}$ films.

\section{Experiments}

The $\mathrm{N}$-doped $\mathrm{TiO}_{2}$ thin films were prepared inside a stainless steel reaction chamber. A $\mathrm{KrF}$ excimer laser (wavelength: $248 \mathrm{~nm}$, pulse frequency: $10 \mathrm{~Hz}$, pulse duration: $25 \mathrm{~ns}$ ) was used for the irradiation of $\mathrm{N}: \mathrm{TiO}_{2}$ targets. The target was prepared from $\mathrm{TiN}$ and $\mathrm{TiO}_{2}$ powders (molar ratio $1: 3$ ) by pressing at $5 \mathrm{MPa}$ and sintered at $1100^{\circ} \mathrm{C}$ for $4 \mathrm{~h}$. The laser beam incidence angle onto the target was chosen of about $35^{\circ}$. The incident laser fluence on the target surface was set at about $2.5 \mathrm{~J} / \mathrm{cm}^{2}$.

To avoid piercing, the target was rotated at $10 \mathrm{rpm}$. And laser spot was scanned on the target surface to prepare large area film of $50 \mathrm{~mm}$ in diameter. The substrate is a round normal glass slip with $50 \mathrm{~mm}$ in diameter, its temperature was controlled from room temperature (RT) to $400^{\circ} \mathrm{C}$. The dynamic ambient gas pressure during the irradiations was kept at $1 \mathrm{~Pa}$ by feeding pure oxygen and nitrogen gas (99.9\%, ratio: $\mathrm{O}_{2}: \mathrm{N}_{2}=1: 1$ ) into the chamber for reduction the desorption loss in vacuum. After the preparation was completed, the sample was cooled down to RT with the same oxygen gas pressure.

The sample surface morphology was investigated by domestic CSPM5000 atomic force microscopy (AFM) test. Optical transmission spectra in the near UV and visible spectral regions were studied by PerkinElmer Lamda 950 UV/VIS spectrometer. The Raman spectra test was performed at room temperature with a Renishaw Invia Reflex confocal micro-Raman apparatus with $\mathrm{He}-\mathrm{Cd}$ laser emitting at $325 \mathrm{~nm}$.
The photocatalytic activity of the $\mathrm{N}$-doped $\mathrm{TiO}_{2}$ films with surface area of about $18 \mathrm{~cm}^{2}$ was studied by decompositing organic methyl orange (MO) dye in aqueous solution. The initial concentration of MO solution is $2 \mathrm{mg} / \mathrm{L}$, and the total solution is about $80 \mathrm{~mL}$. A tungsten halogen lamp was used as visible light source with $180 \mathrm{~mW} / \mathrm{cm}^{2}$ power density on the surface of the MO solution. During the photodegradation experiments, the absorbance of the solution was measured at $460 \mathrm{~nm}$ wavelength, which corresponds to the peak absorbance of MO. The intensity of the transmitted detecting light was recorded by a data recorder, whose data sampling interval was set as 2 minutes. This photocatalystic activity evaluating experimental method has not been used before to our knowledge.

\section{Results and Discussion}

3.1. Optical Spectra. The sample color is transparent prepared at RT or $200^{\circ} \mathrm{C}$, and light yellow at $400^{\circ} \mathrm{C}$. Figure 1 shows the transmission spectra of $\mathrm{N}$-doped $\mathrm{TiO}_{2}$ films prepared under different temperature. The absorption edges shift toward longer wavelengths from $300 \mathrm{~nm}$ to $350 \mathrm{~nm}$ with the increase of the substrate temperature, indicating a decrease in the band gap of the films, which may due to the $\mathrm{N}$ composition increase with the increasing temperature. This is different from the results suggested by Farkas et al. [47]. Another reason is the grain size increases with increasing temperature, resulting to weak quantum size effects causing the red-shift of the absorption edge [48]. X-ray photoelectron spectra measurement should be performed to detect the state and component of $\mathrm{N}$ element in the films. The $\mathrm{N}$ element is usually formed as $\mathrm{TiO}_{2-x} \mathrm{~N}_{x}$ in films prepared by PLD method [42, 43, 47].

3.2. AFM Measurements. Figure 2 shows the AFM images of $\mathrm{N}$-doped $\mathrm{TiO}_{2}$ films prepared at room temperature, $200^{\circ} \mathrm{C}$, and $400^{\circ} \mathrm{C}$. The grain sizes are $18.5,19.2$, and $28.1 \mathrm{~nm}$, and their root mean square (rms) of roughness is 3.32 , 3.96 , and $6.73 \mathrm{~nm}$, respectively. This is in agreement with results obtained by Suda et al. [37]. With the temperature increasing, the grain size and roughness increase, which suggests an increase of crystallinity of the films, and inducing red-shift in absorption spectrum because of quantum size effect.

3.3. Raman Spectra. The micro-Raman spectra of $\mathrm{TiO}_{2}$ films are shown in Figure 3. It can be seen that intense Raman peak does not occur until temperature reaches $400^{\circ} \mathrm{C}$, indicating the crystallization realized at that point. This is in accord with that in [48]. In our experiments, only anatase structures appearing as the typical Raman modes at 145, 198, 396, 517 , and $640 \mathrm{~cm}^{-1}$ are assigned to the $E_{\mathrm{g}}, E_{\mathrm{g}}, B_{1 \mathrm{~g}}, A_{1 \mathrm{~g}}$, and $E_{\mathrm{g}}$ modes, respectively. The strongest mode at $145 \mathrm{~cm}^{-1}$ indicates that the anatase phase with a long-range order has been obtained [49].

3.4. Photocatalystic Activity. Shinguu et al. proposed a reflectance method to evaluate the photodecomposition rate of $\mathrm{TiO}_{2}$ films [41]. We have used the conductivity 
TABLE 1: Preparation of $\mathrm{TiO}_{2}$ thin films by PLD method.

\begin{tabular}{|c|c|c|c|c|c|c|c|}
\hline Laser & Substrate & Target & Dopant & Crystalline phase & Ambient air & Photocatalytic activity ${ }^{*}$ & Year Ref. \\
\hline Nd:YAG,532 nm & glass & $\mathrm{TiO}_{2}$ & - & rutile & $\mathrm{O}_{2}$ & - & $1999[38]$ \\
\hline $\operatorname{ArF} 193 \mathrm{~nm}$ & Mica, quartz, Si & $\mathrm{TiO}_{2}$ & - & Rutile, anatase & $\mathrm{Ar}$ & - & 2002 [39] \\
\hline ArF 193 nm & $\alpha-\mathrm{Al}_{2} \mathrm{O}_{3}$ & $\mathrm{Ti}$ & - & Rutile, anatase & $\mathrm{O}_{2}$ & - & $2004[40]$ \\
\hline Nd:YAG,266 nm & $\mathrm{Si}$ & $\mathrm{TiO}_{2}$ & - & Rutile, anatase & $\mathrm{O}_{2}$ & $\mathrm{MB}$, anatase with clusters & $2005[34]$ \\
\hline Nd:YAG,532 nm & $\mathrm{SiO}_{2}$ (corning 7059) & $\mathrm{Ti}, \mathrm{TiO}, \mathrm{TiO}_{2}, \mathrm{TiN}$ & $\mathrm{N}$ & anatase & $\mathrm{O}_{2}, \mathrm{~N}_{2}$ & $\mathrm{MB}$, TiN target & 2005 [37] \\
\hline Nd:YAG,532 nm & Glass & $\mathrm{Ti}$ & $\mathrm{N}$ & anatase & $\mathrm{NH}_{3} / \mathrm{N}_{2} / \mathrm{O}_{2}$ & - & $2006[26]$ \\
\hline $\mathrm{KrF} 248 \mathrm{~nm}$ & Si or quartz glass & $\mathrm{Ti}, \mathrm{TiO}_{2}, \mathrm{WO}_{3}$ & multilayer & - & $\mathrm{O}_{2}$ & $\mathrm{MB}, \mathrm{WO}_{3}, 5 \%$ & $2006[41]$ \\
\hline Nd:YAG, $1064 \mathrm{~nm}$ & quartz glass & $\mathrm{TiO}_{2}$ & $\mathrm{~N}$ & anatase & $\mathrm{O}_{2}, \mathrm{~N}_{2}$ & $\mathrm{MB}, \mathrm{MO}, \mathrm{Eg}=1.0 \mathrm{eV}, 2.5 \mathrm{eV}$ & $2008[42]$ \\
\hline $\mathrm{KrF} 248 \mathrm{~nm}$ & LSAT & $\mathrm{TiO}_{2}, \mathrm{TiN}$ & $\mathrm{N}$ & anatase & $\mathrm{O}_{2}$ & - & $2008[43]$ \\
\hline Nd:YAG,266 nm & quartz & $\mathrm{TiO}_{2}, \mathrm{La}_{2} \mathrm{O}_{3}$ & $\mathrm{La}$ & Rutile & $\mathrm{N}_{2}$ & $\mathrm{MB}, 900^{\circ} \mathrm{C}$ postannealing & $2009[44]$ \\
\hline $\mathrm{KrF} 248 \mathrm{~nm}$ & glass & $\mathrm{TiO}_{2}$ & $\mathrm{C}, \mathrm{N}$ & anatase & $\mathrm{O}_{2}, \mathrm{~N}_{2}, \mathrm{CH}_{4}$ & $\mathrm{Cr}(\mathrm{II}), \mathrm{N}$ doped & $2010[25]$ \\
\hline $\mathrm{KrF} 248 \mathrm{~nm}$ & $\mathrm{SiO}_{2}$ quartz & $\mathrm{TiO}_{2}$ & $\mathrm{~N}$ & anatase & $\mathrm{O}_{2}, \mathrm{~N}_{2}$ & - & $2010[45]$ \\
\hline $\mathrm{KrF} 248 \mathrm{~nm}$ & $\mathrm{SiO}_{2}$ quartz & $\mathrm{Ag}, \mathrm{TiO}_{2}$ & - & anatase & $\mathrm{O}_{2}$ & $\mathrm{MB}$ & $2011[33]$ \\
\hline
\end{tabular}

* Organic compound for decomposition and optimal conditions obtained. MO: methyl orange, MB: methylene blue, $\mathrm{Cr}$ (II): toxic Chromium ion, it can be photoreducted to $\mathrm{Cr}$ (III) state.

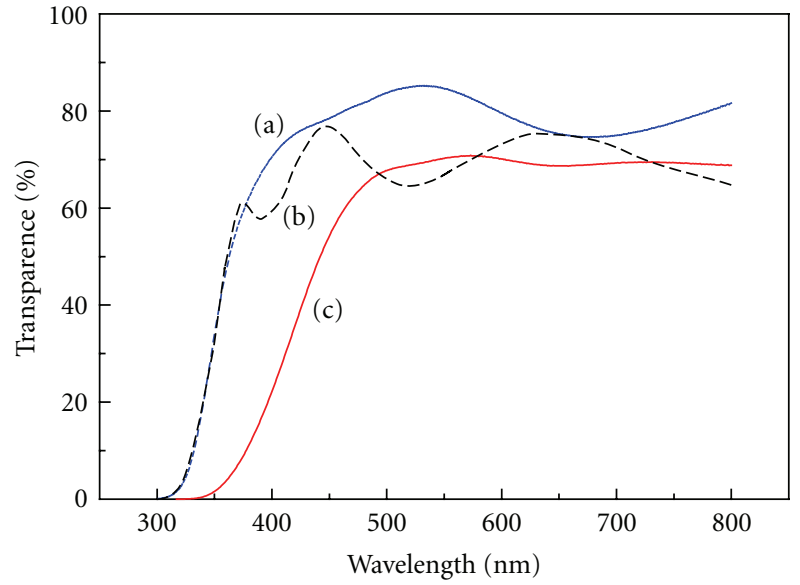

(a) RT

(b) $200^{\circ} \mathrm{C}$

(c) $400^{\circ} \mathrm{C}$

Figure 1: Transmission spectra of $\mathrm{N}$-doped $\mathrm{TiO}_{2}$ films prepared at different temperature, (a) RT, (b) $200^{\circ} \mathrm{C}$, (c) $400^{\circ} \mathrm{C}$.

method to check the rate $[35,50]$. Recently, we developed a transmittance method to detect the concentration of the $\mathrm{MO}$ to evaluate the photocatalystic activity of the $\mathrm{N}$-doped $\mathrm{TiO}_{2}$ films. The setup is shown in Figure 4. The light source can be visible or UV light as demand. The LED light is $460 \mathrm{~nm}$ or $650 \mathrm{~nm}$ wavelength, which corresponds to the peak absorbance of $\mathrm{MO}$ or MB. The relationship between the transmittance and concentration was calibrated. This method has the advantages of continuous, automatic check without disturbing the reaction process, and avoiding danger to operator when use UV light source, and so forth.

Figure 5 shows the decomposition rate with time of $\mathrm{MO}$ using $\mathrm{N}$-doped $\mathrm{TiO}_{2}$ films prepared at different temperatures under visible light irradiation. It is clearly shown that photocatalystic activity of $\mathrm{N}$-doped $\mathrm{TiO}_{2}$ films strongly depends on the preparation temperature. $\mathrm{MO}$ was almost decomposed completely after 4 hours for sample prepared at $400^{\circ} \mathrm{C}$. This is due to band gap narrowing by nitrogen atom, larger surface area, and better crystallization at higher temperature.

3.5. Discussions. $\mathrm{TiO}_{2}$ film is a versatile material for use in many fields. For photocatalysis applications, the main problems are to narrow the band gap for visible light and to retard the recombination of electrons and holes. Anion or cation doping, or codoping, noble mental, and multilayer structure modification methods, and so forth have been proposed to improve $\mathrm{TiO}_{2}$ photocatalystic activity till now. PLD technique is a widely used method to prepare oxide materials; it is easy to change the growth parameters to get various properties of doped films. Its controllability and reproducibility provide much convenience for base research of films materials with high melting point or multicomponent.

In our $\mathrm{N}$-doped $\mathrm{TiO}_{2}$ preparation experiments, laser pulses with intensity density about $1.0 \times 10^{12} \mathrm{~W} / \mathrm{m}^{2}$ was irradiated onto the surface of $\mathrm{N}: \mathrm{TiO}_{2}$ ceramic target. Plasma plumes were produced. Energetic $\mathrm{N}$ ion, Ti ion, and $\mathrm{O}$ ion, as well as $\mathrm{N}$ containing $\mathrm{TiO}_{2}$ micrograins are ejected from the target surface to the glass substrate. The $\mathrm{TiO}_{2}$ crystal nucleus formed and became larger with the subsequent plasma plume until they combined with each other to form thin film. During this process, $\mathrm{N}$ element was easier to incorporate into the lattice of $\mathrm{TiO}_{2}$ as oxygen substitutor or interstitial atoms than that using $\mathrm{N}_{2}$ air as $\mathrm{N}$ source, due to it got energy from the laser irradiation directly $[37,43]$. Higher substrate temperature, $400^{\circ} \mathrm{C}$ in our procedure, is beneficial to form crystallization, and larger grains as shown in the AFM image. Large grains and high rms of roughness provide large surface area resulting to big contact chance of organic compound. Mole ratio of $\mathrm{TiN}$ and $\mathrm{TiO}_{2}$ in target is $1: 3$, but we can speculate that the corresponding ratio inside the film is smaller due to relative easier desorption of small mass atom 


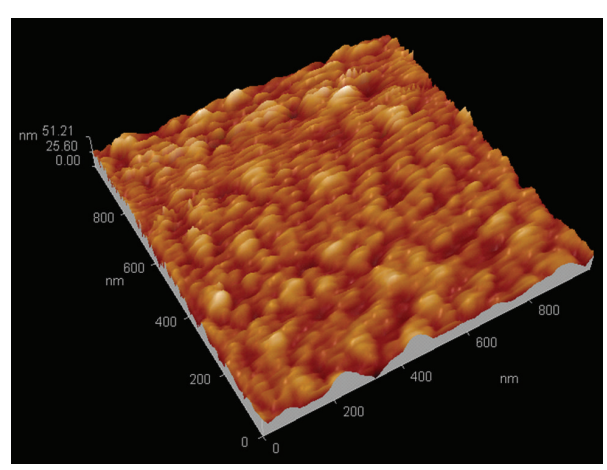

(a)

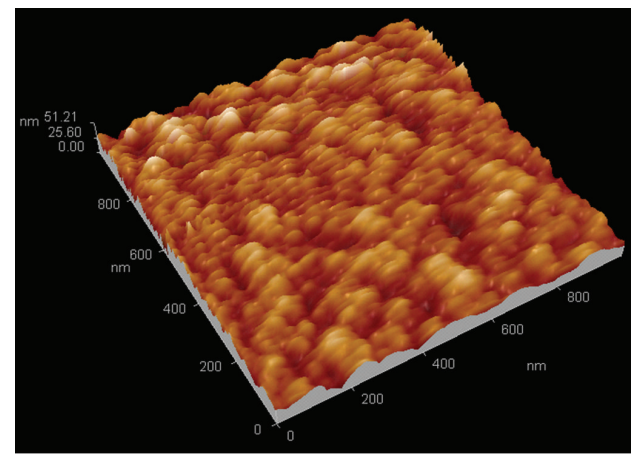

(b)

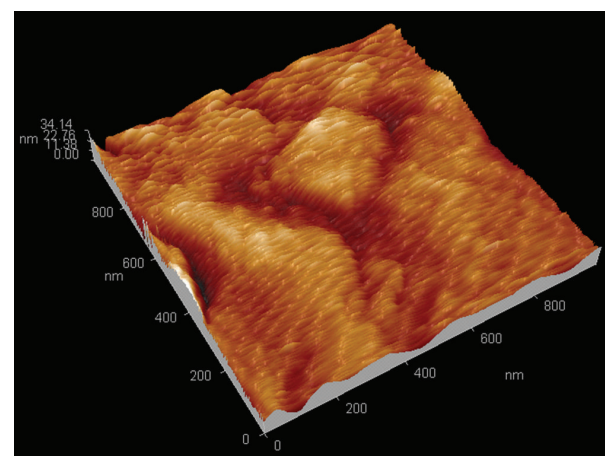

(c)

Figure 2: AFM images of the surface morphology of $\mathrm{N}$-doped $\mathrm{TiO}_{2}$ films under different temperature, (a) $\mathrm{RT}$, (b) $200^{\circ} \mathrm{C}$, and (c) $400^{\circ} \mathrm{C}$.

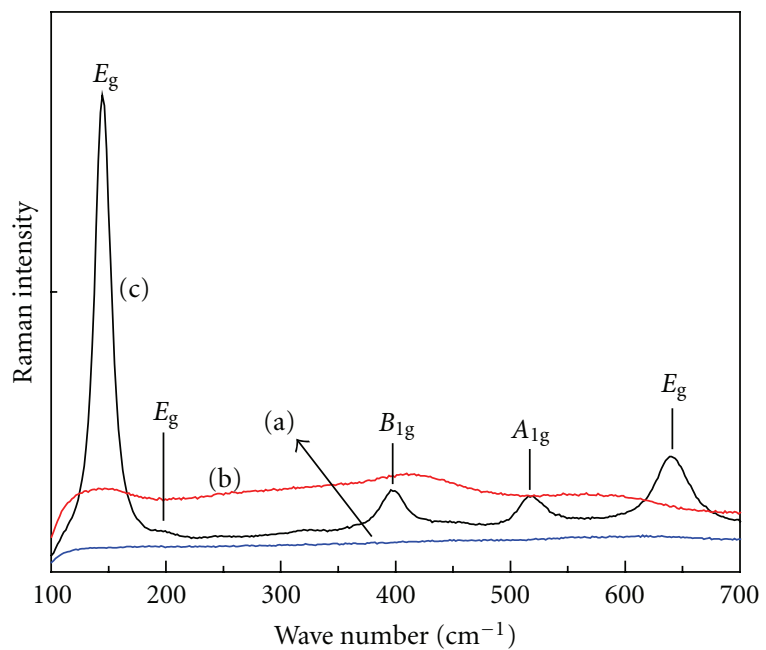
(a) RT
(b) $200^{\circ} \mathrm{C}$
(c) $400^{\circ} \mathrm{C}$

FIgURE 3: Raman spectra of N-doped $\mathrm{TiO}_{2}$ films prepared at different temperature, (a) RT, (b) $200^{\circ} \mathrm{C}$, (c) $400^{\circ} \mathrm{C}$.

from the film surface [31]. MO was almost photodegraded completely using visible light after 4 hours.

Tachikawa et al. concluded that the adsorption dynamics of substrates and organic compound, the electronic interaction between $\mathrm{TiO}_{2}$ and adsorbents, and the band structure

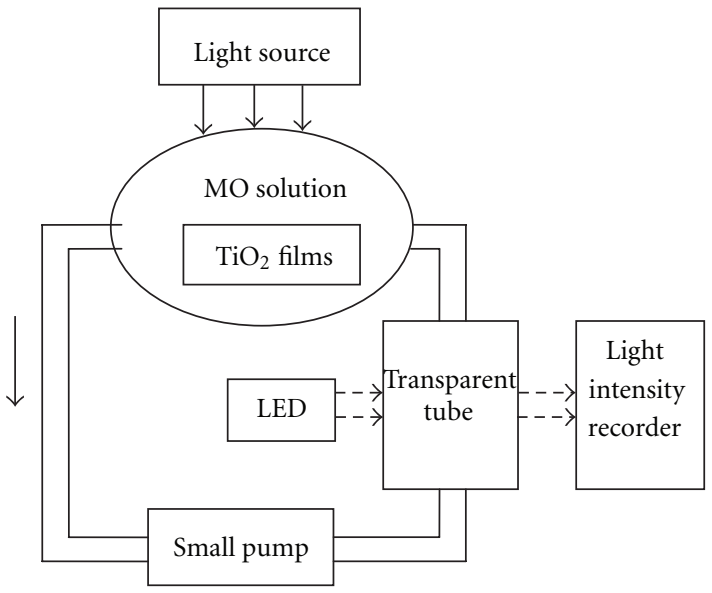

FIGURE 4: The schematic diagram of experimental setup for automatic detecting the photodecomposition rate. The whole setup is put in an aluminum box. The data record interval can be set from 1 minute to 1 hour. MO solution: methyl orange solution.

and morphology of $\mathrm{TiO}_{2}$ nanomaterials are crucial factors for establishing efficient photocatalytic reaction systems. The morphology of $\mathrm{TiO}_{2}$ affects the charge recombination dynamics, and anisotropic adsorption was found in recent research [51].

Photocatalysis is a complex process involving chemical and physical reactions. The researchers should combine 


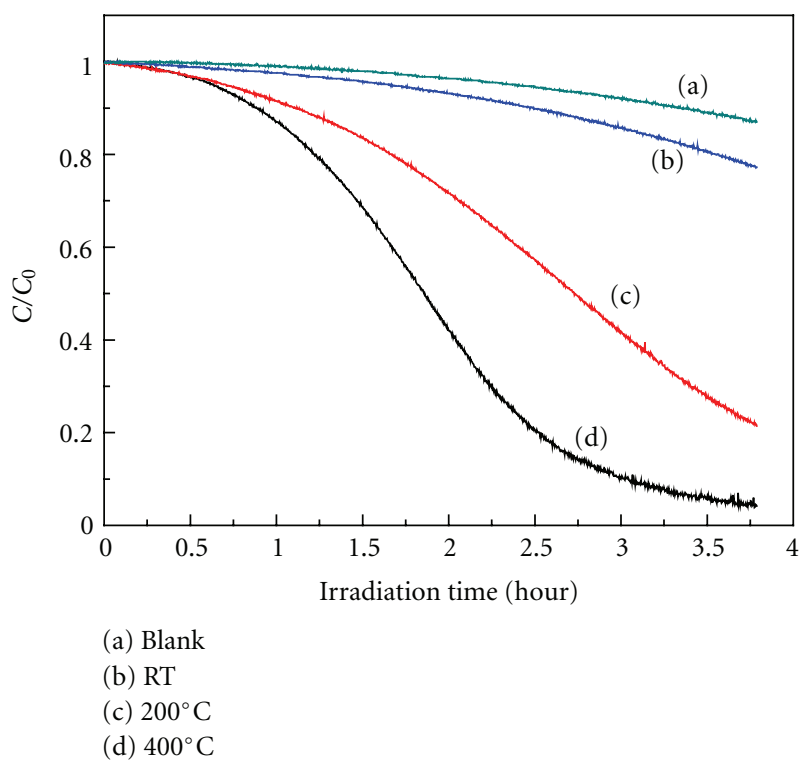

Figure 5: Decomposition rate with time of MO using N-doped $\mathrm{TiO}_{2}$ films prepared at different temperature under visible light irradiation, (a) without $\mathrm{TiO}_{2}$, (b) $\mathrm{RT}$, (c) $200^{\circ} \mathrm{C}$, (d) $400^{\circ} \mathrm{C}$. $\mathrm{C}_{0}$ is the initial concentration of Methyl orange about $2 \mathrm{mg} / \mathrm{L}$, and $C$ is the concentration changing with time.

chemical methods and physical methods to overcome problems from photocatalystic material modification to degrade organic compound. For example, Rimeh et al. prepared $\mathrm{Ti} / \mathrm{TiO}_{2}$ electrode by PLD technique and obtained a degradation rate of almost $75 \%$ of chlortetracycline within 2 hours [52].

\section{Conclusions}

Fascinating $\mathrm{TiO}_{2}$ films were worldwide researched using various preparing method. PLD technique is a versatile method for preparing films of oxide materials. Its advantages of controllability and reproducibility are suitable for basis research for preparing various properties of $\mathrm{TiO}_{2}$ films. Some recent experimental results obtained in our group were presented. $\mathrm{N}$-doped $\mathrm{TiO}_{2}$ anatase films were prepared at substrate temperature from RT to $400^{\circ} \mathrm{C}$ by PLD method using a novel ceramic target of mixture of $\mathrm{TiN}$ and $\mathrm{TiO}_{2}$ and were characterized by UV/Vis optical spectra, AFM, Raman spectra, and photocatalystic activity for decomposition of methyl orange. It was found that the film crystallinity, the visible light response, and decomposition rate were significantly improved at higher temperature. New method of continuous autodetecting the solution optical transmission for evaluating the photodecomposition dynamic process was developed.

\section{Acknowledgment}

Financial support by Shenzhen basic research project of science and technology (JC201005280419A) is gratefully acknowledged.

\section{References}

[1] U. Diebold, "The surface science of titanium dioxide," Surface Science Reports, vol. 48, no. 5-8, pp. 53-229, 2003.

[2] A. Fujishima, X. Zhang, and D. A. Tryk, " $\mathrm{TiO}_{2}$ photocatalysis and related surface phenomena," Surface Science Reports, vol. 63, no. 12, pp. 515-582, 2008.

[3] M. A. Henderson, "A surface science perspective on $\mathrm{TiO}_{2}$ photocatalysis," Surface Science Reports, vol. 66, no. 6-7, pp. 185297, 2011.

[4] N. E. Stankova, I. G. Dimitrov, T. R. Stoyanchov, and P. A. Atanasov, "Optical and gas sensing properties of thick $\mathrm{TiO}_{2}$ films grown by laser deposition," Applied Surface Science, vol. 254, no. 4, pp. 1268-1272, 2007.

[5] N. Todorova, T. Giannakopoulou, G. Romanos, T. Vaimakis, J. $\mathrm{Yu}$, and C. Trapalis, "Preparation of fluorine-doped $\mathrm{TiO}_{2}$ photocatalysts with controlled crystalline structure," International Journal of Photoenergy, vol. 2008, Article ID 534038, 9 pages, 2008.

[6] M. Farbod and M. Khademalrasool, "Synthesis of $\mathrm{TiO}_{2}$ nanoparticles by a combined sol-gel ball milling method and nvestigation of nanoparticle size effect on their photocatalytic activities," Powder Technology, vol. 214, pp. 344-348, 2011.

[7] A. M. More, T. P. Gujar, J. L. Gunjakar, C. D. Lokhande, and O. S. Joo, "Growth of $\mathrm{TiO}_{2}$ nanorods by chemical bath deposition method," Applied Surface Science, vol. 255, no. 5, pp. 26822687, 2008.

[8] H. Zhu, J. Yang, S. Feng, M. Liu, J. Zhang, and G. Li, "Growth of $\mathrm{TiO}_{2}$ nanosheet-array thin films by quick chemical bath deposition for dye-sensitized solar cells," Applied Physics A, vol. 105, pp. 769-774, 2011.

[9] J. K. Yao, H. Y. Li, Z. X. Fan et al., "Comparison of $\mathrm{TiO}_{2}$ and $\mathrm{ZrO}_{2}$ films deposited by electron-beam evaporation and by sol-gel process," Chinese Physics Letters, vol. 24, no. 7, article 049, pp. 1964-1966, 2007.

[10] Ö. Duyar, F. Placido, and H. Zafer Durusoy, "Optimization of $\mathrm{TiO}_{2}$ films prepared by reactive electron beam evaporation of $\mathrm{Ti}_{3} \mathrm{O}_{5}$," Journal of Physics D, vol. 41, no. 9, Article ID 095307, 2008.

[11] B. Cojocaru, Ş. Neaţu, E. Sacaliuc-Pârvulescu, F. Lévy, V. I. Pârvulescu, and H. Garcia, "Influence of gold particle size on the photocatalytic activity for acetone oxidation of $\mathrm{Au} / \mathrm{TiO}_{2}$ catalysts prepared by dc-magnetron sputtering," Applied Catalysis B, vol. 107, pp. 140-149, 2011.

[12] D. Y. Chen, C. C. Tsao, and C. Y. Hsu, "Photocatalytic $\mathrm{TiO}_{2}$ thin films deposited on flexible substrates by radio frequency (RF) reactive magnetron sputtering," Current Applied Physics, vol. 12, pp. 179-183, 2012.

[13] J. C. Yu, W. Ho, J. Yu, S. K. Hark, and K. Iu, "Effects of trifluoroacetic acid modification on the surface microstructures and photocatalytic activity of mesoporous $\mathrm{TiO}_{2}$ thin films," Langmuir, vol. 19, no. 9, pp. 3889-3896, 2003.

[14] S. Zhan, D. Chen, X. Jiao, and C. Tao, "Long $\mathrm{TiO}_{2}$ hollow fibers with mesoporous walls: sol-gel combined electrospun fabrication and photocatalytic properties," Journal of Physical Chemistry B, vol. 110, no. 23, pp. 11199-11204, 2006.

[15] J. Zhu, F. Chen, J. Zhang, H. Chen, and M. Anpo, "Fe3+- $\mathrm{TiO}_{2}$ photocatalysts prepared by combining sol-gel method with hydrothermal treatment and their characterization," Journal of Photochemistry and Photobiology A, vol. 180, no. 1-2, pp. 196204, 2006.

[16] N. Arconada, A. Durán, S. Suárez et al., "Synthesis and photocatalytic properties of dense and porous $\mathrm{TiO}_{2}$-anatase thin 
films prepared by sol-gel," Applied Catalysis B, vol. 86, no. 1-2, pp. 1-7, 2009.

[17] Z. Luo, H. Cai, X. Ren, J. Liu, W. Hong, and P. Zhang, "Hydrophilicity of titanium oxide coatings with the addition of silica," Materials Science and Engineering B, vol. 138, no. 2, pp. 151-156, 2007.

[18] J. L. Falconer and K. A. Magrini-Bair, "Photocatalytic and thermal catalytic oxidation of acetaldehyde on $\mathrm{Pt} / \mathrm{TiO}_{2}$," Journal of Catalysis, vol. 179, no. 1, pp. 171-178, 1998.

[19] J. Zhang, C. Pan, P. Fang, J. Wei, and R. Xiong, "Mo + $\mathrm{C}$ codoped $\mathrm{TiO}_{2}$ using thermal oxidation for enhancing photocatalytic activity," ACS Applied Materials and Interfaces, vol. 2, no. 4, pp. 1173-1176, 2010.

[20] R. Long and N. J. English, "Electronic properties of anatase$\mathrm{TiO}_{2}$ codoped by cation-pairs from hybrid density functional theory calculations," Chemical Physics Letters, no. 513, pp. 218-223, 2011.

[21] D. J. Mowbray, J. I. Martinez, G. J. M. Lastra, K. S. Thygesen, and K. W. Jacobsen, "Stability and electronic properties of $\mathrm{TiO}_{2}$ nanostructures with and without $\mathrm{B}$ and $\mathrm{N}$ doping," Journal of Physical Chemistry C, vol. 113, no. 28, pp. 1230112308, 2009.

[22] R. Long and N. J. English, "First-principles calculation of nitrogen-tungsten codoping effects on the band structure of anatase-titania," Applied Physics Letters, vol. 94, no. 13, Article ID 132102, 2009.

[23] R. Asahi, T. Morikawa, T. Ohwaki, K. Aoki, and Y. Taga, "Visible-light photocatalysis in nitrogen-doped titanium oxides," Science, vol. 293, no. 5528, pp. 269-271, 2001.

[24] M. Batzill, E. H. Morales, and U. Diebold, "Influence of nitrogen doping on the defect formation and surface properties of $\mathrm{TiO}_{2}$ rutile and anatase," Physical Review Letters, vol. 96, no. 2, Article ID 026103, 4 pages, 2006.

[25] G. Socol, Y. Gnatyuk, N. Stefan et al., "Photocatalytic activity of pulsed laser deposited $\mathrm{TiO}_{2}$ thin films in $\mathrm{N}_{2}, \mathrm{O}_{2}$ and $\mathrm{CH}_{4}$," Thin Solid Films, vol. 518, no. 16, pp. 4648-4653, 2010.

[26] P. Xu, L. Mi, and P. N. Wang, "Improved optical response for N-doped anatase $\mathrm{TiO}_{2}$ films prepared by pulsed laser deposition in $\mathrm{N}_{2} / \mathrm{NH}_{3} / \mathrm{O}_{2}$ mixture," Journal of Crystal Growth, vol. 289, no. 2, pp. 433-439, 2006.

[27] V. Balek, D. Li, J. Šubrt et al., "Characterization of nitrogen and fluorine co-doped titania photocatalyst: effect of temperature on microstructure and surface activity properties," Journal of Physics and Chemistry of Solids, vol. 68, no. 5-6, pp. 770-774, 2007.

[28] M. Yuan, J. Zhang, S. Yan et al., "Effect of $\mathrm{Nd}_{2} \mathrm{O}_{3}$ addition on the surface phase of $\mathrm{TiO}_{2}$ and photocatalytic activity studied by UV Raman spectroscopy," Journal of Alloys and Compounds, vol. 509, no. 21, pp. 6227-6235, 2011.

[29] Y. Z. Qu, M. M. Yao, F. Li, and X. H. Sun, "Microstructures and Photocatalytic Properties of $\mathrm{Fe}^{3+} / \mathrm{Ce}^{3+}$ Codoped Nanocrystalline $\mathrm{TiO}_{2}$ Films," Water, Air and Soil Pollution, vol. 221, no. 1-4, pp. 13-21, 2011.

[30] Z. Luo, H. Cai, X. Ren, J. Liu, W. Hong, and P. Zhang, "Hydrophilicity of titanium oxide coatings with the addition of silica," Materials Science and Engineering B, vol. 138, no. 2, pp. 151-156, 2007.

[31] J. Schou, "Physical aspects of the pulsed laser deposition technique: the stoichiometric transfer of material from target to film," Applied Surface Science, vol. 255, no. 10, pp. 51915198, 2009.

[32] N. Sato, M. Matsuda, M. Yoshinaga, T. Nakamura, S. Sato, and A. Muramatsu, "The synthesis and photocatalytic properties of nitrogen doped $\mathrm{TiO}_{2}$ films prepared using the AC-PLD method," Topics in Catalysis, vol. 52, no. 11, pp. 1592-1597, 2009.

[33] G. Sauthier, A. Pérez del Pino, A. Figueras, and E. György, "Synthesis and characterization of Ag nanoparticles and Agloaded $\mathrm{TiO}_{2}$ photocatalysts," Journal of the American Ceramic Society, vol. 94, no. 11, pp. 3780-3786, 2011.

[34] T. Yoshida, Y. Fukami, M. Okoshi, and N. Inoue, "Improvement of photocatalytic efficiency of $\mathrm{TiO}_{2}$ thin films prepared by pulsed laser deposition," Japanese Journal of Applied Physics, Part 1, vol. 44, no. 5, pp. 3059-3062, 2005.

[35] Z. Luo, L. Song, H. Cai, J. Liu, W. Hong, and J. Huang, "Photocatalytic De-chlorination of chlorinated methane by titanium oxide sol," Journal of Inorganic Materials, vol. 21, no. 1, pp. 145-149, 2006.

[36] R. K. Thareja and A. Mohanta, "Gas suspended ZnO clusters and pulsed laser deposition of $\mathrm{ZnO}$ thin film," Physica Status Solidi, no. 5, pp. 1413-1416, 2010.

[37] Y. Suda, H. Kawasaki, T. Ueda, and T. Ohshima, "Preparation of nitrogen-doped titanium oxide thin film using a PLD method as parameters of target material and nitrogen concentration ratio in nitrogen/oxygen gas mixture," Thin Solid Films, vol. 475, no. 1-2, pp. 337-341, 2005.

[38] L. Escobar-Alarcón, E. Haro-Poniatowski, M. A. CamachoLópez, M. Fernández-Guasti, J. Jímenez-Jarquín, and A. Sánchez-Pineda, "Structural characterization of $\mathrm{TiO}_{2}$ thin films obtained by pulsed laser deposition," Applied Surface Science, vol. 137, no. 1-3, pp. 38-44, 1999.

[39] N. Koshizaki, A. Narazaki, and T. Sasaki, "Preparation of nanocrystalline titania films by pulsed laser deposition at room temperature," Applied Surface Science, vol. 197-198, pp. 624-627, 2002.

[40] S. I. Kitazawa, Y. Choi, and S. Yamamoto, "In situ optical spectroscopy of PLD of nano-structured $\mathrm{TiO}_{2}$," Vacuum, vol. 74, no. 3-4, pp. 637-642, 2004.

[41] H. Shinguu, M. M. H. Bhuiyan, T. Ikegami, and K. Ebihara, "Preparation of $\mathrm{TiO}_{2} / \mathrm{WO}_{3}$ multilayer thin film by PLD method and its catalytic response to visible light," Thin Solid Films, vol. 506-507, pp. 111-114, 2006.

[42] L. Zhao, Q. Jiang, and J. Lian, "Visible-light photocatalytic activity of nitrogen-doped $\mathrm{TiO}_{2}$ thin film prepared by pulsed laser deposition," Applied Surface Science, vol. 254, no. 15, pp. 4620-4625, 2008.

[43] T. L. Chen, Y. Hirose, T. Hitosugi, and T. Hasegawa, "One unitcell seed layer induced epitaxial growth of heavily nitrogen doped anatase $\mathrm{TiO}_{2}$ films," Journal of Physics D, vol. 41, no. 6, Article ID 062005, 2008.

[44] T. Ando, T. Wakamatsu, K. Masuda et al., "Photocatalytic behavior of heavy La-doped $\mathrm{TiO}_{2}$ films deposited by pulsed laser deposition using non-sintered target," Applied Surface Science, vol. 255, no. 24, pp. 9688-9690, 2009.

[45] G. Sauthier, F. J. Ferrer, A. Figueras, and E. György, "Growth and characterization of nitrogen-doped $\mathrm{TiO}_{2}$ thin films prepared by reactive pulsed laser deposition," Thin Solid Films, vol. 519, no. 4, pp. 1464-1469, 2010.

[46] S. Somekawa, Y. Kusumoto, M. Ikeda, B. Ahmmad, and Y. Horie, "Fabrication of $\mathrm{N}$-doped $\mathrm{TiO}_{2}$ thin films by laser ablation method: mechanism of $\mathrm{N}$-doping and evaluation of the thin films," Catalysis Communications, vol. 9, no. 3, pp. 437-440, 2008.

[47] B. Farkas, J. Budai, I. Kabalci, P. Heszler, and Z. Geretovszky, "Optical characterization of PLD grown nitrogen-doped $\mathrm{TiO}_{2}$ 
thin films," Applied Surface Science, vol. 254, no. 11, pp. 3484$3488,2008$.

[48] X. Wang, J. Shen, and Q. Pan, "Raman spectroscopy of solgel derived titanium oxide thin films," Journal of Raman Spectroscopy, vol. 42, no. 7, pp. 1578-1582, 2011.

[49] S. Sahoo, A. K. Arora, and V. Sridharan, "Raman line shapes of optical phonons of different symmetries in anatase $\mathrm{TiO}_{2}$ nanocrystals," Journal of Physical Chemistry C, vol. 113, no. 39, pp. 16927-16933, 2009.

[50] Z. Luo, M. Li, H. Cai, and J. Liu, "Conductivity characteristics of DCM solution under photo-oxidation of titanium oxide sol," Journal of Materials Science \& Engineering, vol. 22, no. 4, pp. 523-526, 2004.

[51] T. Tachikawa, M. Fujitsuka, and T. Majima, "Mechanistic insight into the $\mathrm{TiO}_{2}$ photocatalytic reactions: design of new photocatalysts," Journal of Physical Chemistry C, vol. 111, no. 14, pp. 5259-5275, 2007.

[52] D. Rimeh, D. Patrick, K. Ibrahima, E. Khakani, and M. Ali, "Photoelectrocatalytic degradation of chlortetracycline using $\mathrm{Ti} / \mathrm{TiO}_{2}$ nanostructured electrodes deposited by means of a Pulsed Laser Deposition process," Journal of Hazardous Materials, vol. 199-200, pp. 15-24, 2012. 


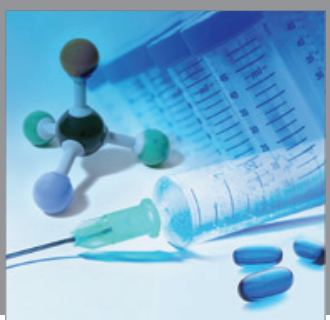

International Journal of

Medicinal Chemistry

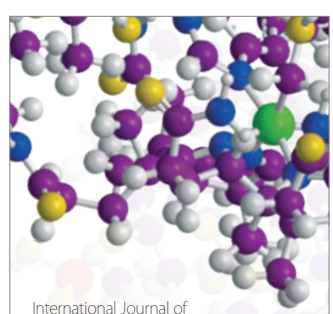

Carbohydrate Chemistry

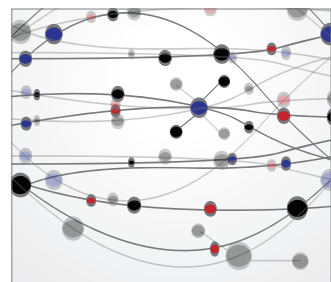

The Scientific World Journal
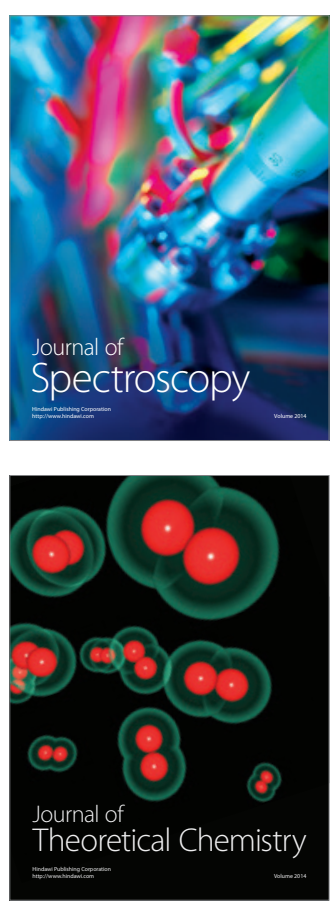
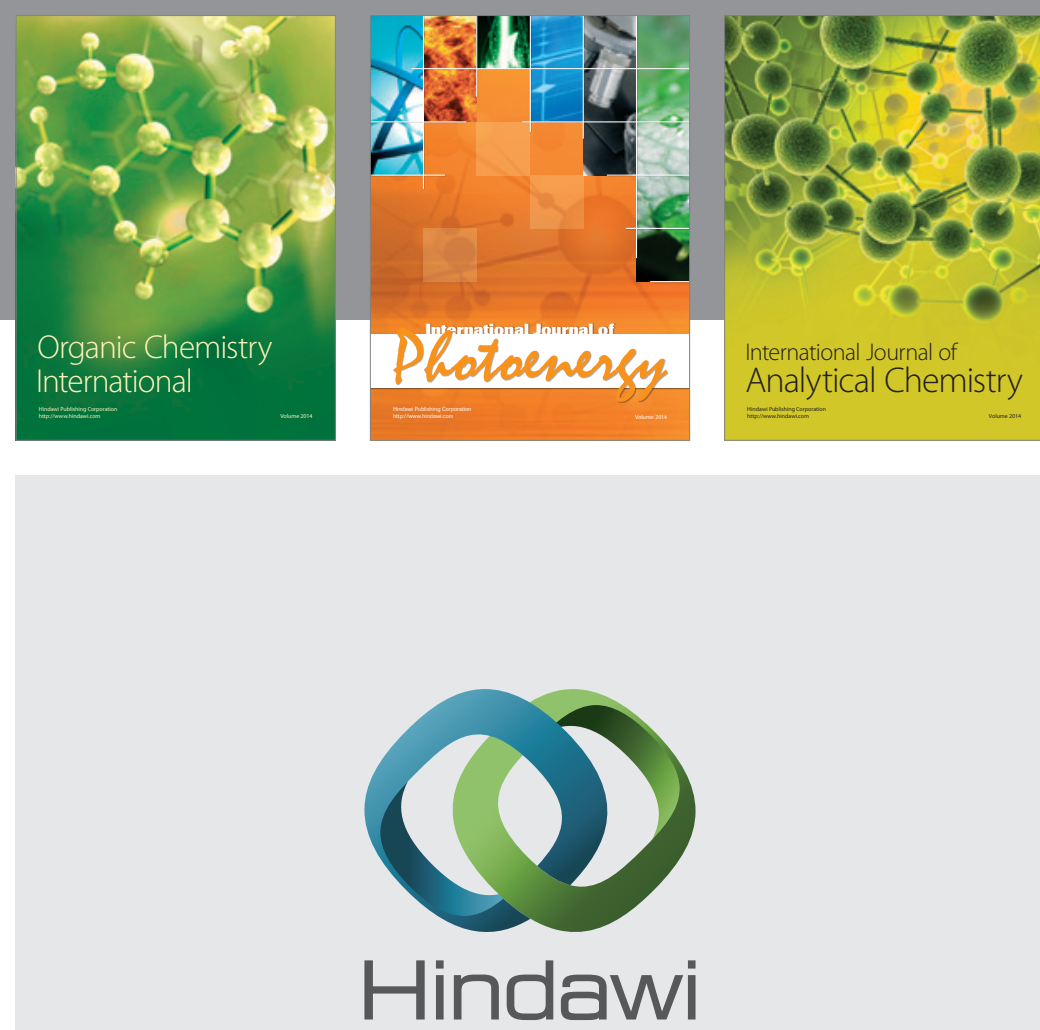

Submit your manuscripts at

http://www.hindawi.com
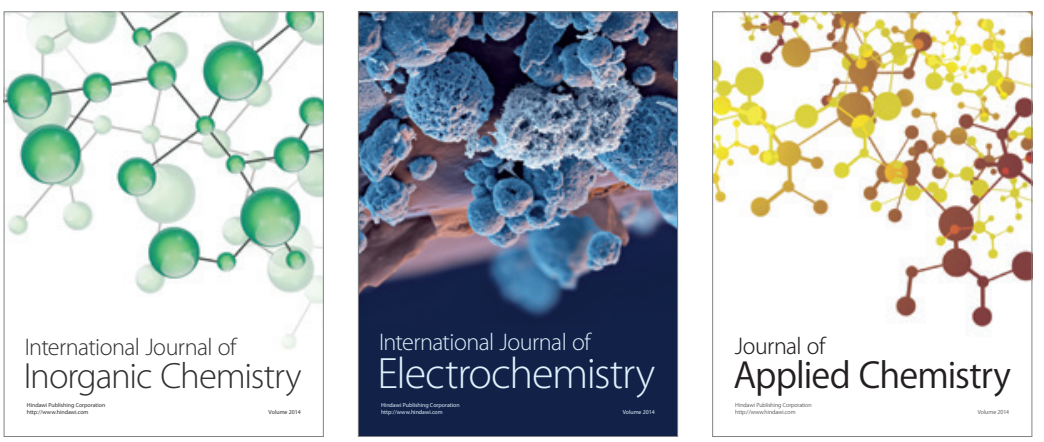

Journal of

Applied Chemistry
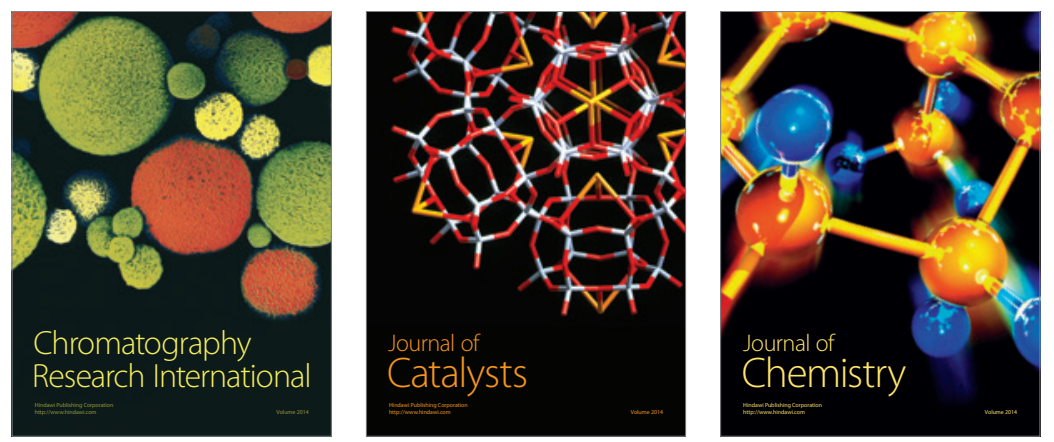
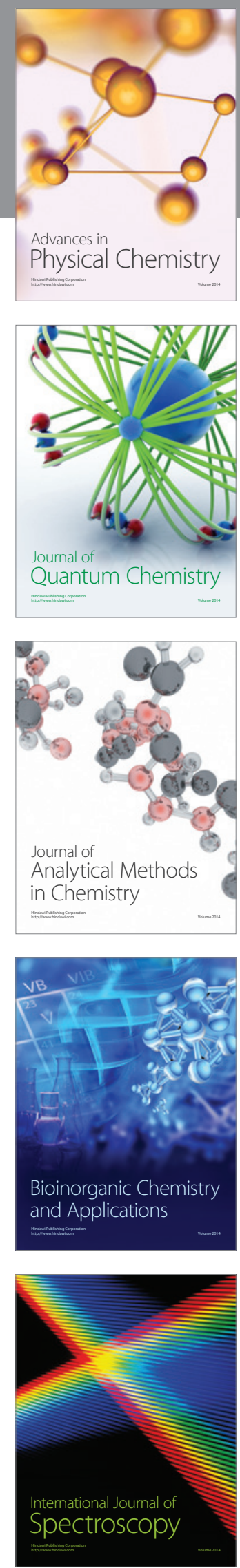